\title{
Pathologic Evaluation of the Supraoptic and Paraventricular Nuclei in Dementia
}

\author{
David Diodati, Lee Cyn-Ang, Andrew Kertesz, Elizabeth Finger
}

\begin{abstract}
Background: The neuropeptide oxytocin, produced in the supraoptic (SON) and paraventricular nuclei (PVN) of the hypothalamus, is now understood to function as a neurotransmitter critical for various aspects of social cognition and pro-social behaviour. While patients with Frontotemporal dementia (FTD) display prominent and progressive deficits in such social behaviours, the integrity of these nuclei in FTD is not known. Methods: We conducted a quantitative neuropathologic examination of the SON and PVN from patients with FTLD with TDP-43 proteinopathy, Alzheimer's disease, Lewy body disease and controls to determine whether significant pathologic changes or neuronal loss may contribute to the striking behavioural symptoms of FTD. Results: Contrary to predictions, we found both nuclei to be free of significant pathologic change (TDP-43) in FTLD. In contrast, tau related pathology was found in the PVN in Alzheimer's disease, and alpha-synuclein pathology in the SON in patients with Lewy body dementia. Conclusions: These results indicate that the SON and PVN are resistant to FTLD TDP-43 pathology. They also support prior suggestions that the SON is resistant to Alzheimer's disease (AD) related pathology, and extend this to demonstrate SON susceptibility to alpha-synuclein pathology in patients with Lewy body dementia.
\end{abstract}

RÉSUMÉ: Évaluation anatomopathologique des noyaux supraoptiques et paraventriculaires dans la démence. Contexte : On sait maintenant que l'ocytocine, un neuropeptide produit dans les noyaux supraoptiques (NSO) et paraventriculaires (NPV) de l'hypothalamus, agit comme un neurotransmetteur dont la fonction est importante pour différents aspects de la cognition sociale et du comportement prosocial. Les patients qui présentent une démence fronto-temporale (DFT) ont des déficits importants et progressifs de ces comportements sociaux. Cependant l'intégrité de ces noyaux dans la DFT n'a pas été étudiée. Méthode : Nous avons effectué un examen neuropathologique quantitatif des NSO et NPV de patients atteints de démence lobaire frontotemporale (DLFT) ayant une protéinopathie TDP-43, une maladie d'Alzheimer, une démence à corps de Lewy ainsi que chez des sujets témoins afin de déterminer si des changements anatomopathologiques importants ou une perte neuronale pouvait contribuer aux symptômes comportementaux évidents de la DFT. Résultats : Contrairement à nos attentes, nous n'avons pas constaté la présence de changements anatomopathologiques significatifs (TDP-43) dans la DLFT. Par contre, nous avons observé la pathologie tau dans le NPV de patients atteints de la maladie d'Alzheimer et des agrégats d'alpha-synucléine dans les NSO des patients atteints de démence à corps de Lewy. Conclusions : Ces résultats indiquent que le NSO et le NPV sont résistants à la pathologie TDP-43 de la DLFT. Ils appuient également les suggestions faites antérieurement à l'effet que le NSO est résistant à la pathologie de la maladie d'Alzheimer et ils démontrent de plus la susceptibilité du NSO aux agrégats d'alpha-syncléine chez les patients atteints de démence à corps de Lewy.

Can J Neurol Sci. 2012; 39: 213-219

Frontotemporal dementia (FTD) is a neurodegenerative disorder featuring striking changes in personality including emotional blunting, increased self-centered behaviour, and poor judgment ${ }^{1-3}$. At the cognitive level, patients with frontotemporal dementia have deficits in emotional processing including loss of empathy ${ }^{4,5}$, decreased emotion recognition ${ }^{6-8}$, and deficits in theory of mind $^{9,10}$. Recent work in humans has demonstrated that the neuropeptide oxytocin may facilitate emotional and social cognition in each of these domains in healthy adults. Oxytocin is produced in the supraoptic (SON) and paraventricular (PVN) nuclei in the hypothalamus ${ }^{11}$. Despite the important role of oxytocin in many aspects of social cognition impaired in patients with FTD, little empirical data concerning the integrity of these nuclei in patients with frontotemporal dementia has been reported.

Oxytocin produced in the hypothalamus and released via the pituitary into the systemic circulation has previously been most strongly associated with uterine contractions and milk ejection during lactation. Oxytocin producing neurons from the SON and PVN also project directly to brain regions involved in reward processing, including the amygdala, nucleus accumbens and medial prefrontal cortex ${ }^{12-16}$. These regions are severely affected by the neuropathologic changes associated with frontotemporal lobar degeneration (FTLD) ${ }^{17-19}$. Thus, damage to oxytocin

From the Cognitive Neurology and Alzheimer Research Centre (DD, AK, EF), St Joseph's Hospital; Department of Pathology (LCA), Department of Clinical Neurological Sciences (AK, EF), Schulich School of Medicine; Department of

Psychology (EF), University of Western Ontario, London, Ontario, Canada. Received June 14, 2011. Final Revisions Submitted October 4, 2011. Correspondence to: Elizabeth Finger, Department of Clinical Neurological Sciences, University of Western Ontario, B10-004, 339 Windermere Rd, London, Ontario, N6A 5A5, Canada. 
projection neurons and synapses in these regions may contribute to the social cognitive deficits in FTD.

In addition to its role in pregnancy, oxytocin is now recognized to be an important mediator of social cognition across species and gender, specifically increasing pro-social behaviours ${ }^{12,20,21}$. In animal models administration of oxytocin increases maternal behaviours including grooming, nesting, and pair bond formation $^{22-24}$. In humans, administration of oxytocin to healthy adults increases trust and cooperative behaviours ${ }^{25,26}$, emotional empathy $^{27}$, facial expression recognition ${ }^{28-30}$, and theory of mind skills $^{31}$. In addition, oxytocin administration to autistic patients facilitates social information processing and decreases repetitive behaviours $^{32,33}$.

Despite the social impairment in FTD and the association between social cognition and oxytocin neuronal systems, little is known about whether FTD related pathology affects the two main nuclei producing oxytocin. Frontotemporal dementia pathology has been examined in other hypothalamic nuclei, including reduced neuron to astrocyte ratios in the suprachiasmatic nucleus ${ }^{34}$ and significant pathologic changes in the lateral tubular nucleus in Pick's disease ${ }^{35}$. One recent study of the hypothalamus and eating disorders in patients with FTD found reduced posterior hypothalamic volumes compared to controls in TDP-43 positive patients, but no changes in the number of vasopressin containing neurons in the $\mathrm{PVN}^{36}$.

Given the deficits in prosocial behaviours, empathy and emotion recognition in FTD, and the mediation of these processes by oxytocin, we hypothesized that damage to oxytocin producing nuclei may contribute to the abnormal social behaviour characteristic of patients with FTD. The purpose of this project was to characterize neurodegenerative pathology of the supraoptic and paraventricular nuclei in patients with autopsy confirmed FTD in comparison to patients with Alzheimer's disease (AD) and Lewy body dementia (LBD). If neuro-pathologic changes in oxytocin producing nuclei give rise to deficits in social cognition, then we predicted that patients with FTD would show more abnormal protein inclusions and/or decreased neuronal densities in the SON and/or PVN compared to patients with Alzheimer's disease, LBD and neurologically healthy comparison individuals.

\section{METHODS}

The autopsy database at London Health Sciences Centre (LHSC) was searched for patients with a final autopsy diagnosis of LBD, AD, or FTLD (excluding corticobasal syndrome or progressive supranuclear palsy (PSP)), excluding cases with other significant associated neuropathological findings such as infections, trauma, neoplasms or stroke. Age-matched controls were also selected from cases without known neurological diseases and no significant neuropathological findings on autopsy. Only cases with availability of the hypothalamus (namely, SON and PVN) either in the paraffin blocks or formalin fixed wet tissue were included. In most cases, fresh samples were taken from the formalin-fixed wet brain tissue and then embedded in paraffin wax for the study. The paraffin tissue blocks were cut in 5 um sections and put on positively charged slides using standard microtome procedure and stained with hematoxylin-eosin (HE). These sections were examined for the presence of the SON and PVN by identifying their characteristic groups of large cell bodies and location. If the SON or the PVN were absent, these blocks were resubmitted for leveling, and stained with $\mathrm{HE}$ at levels $1,5,10,15$, and 20. Leveled slides a

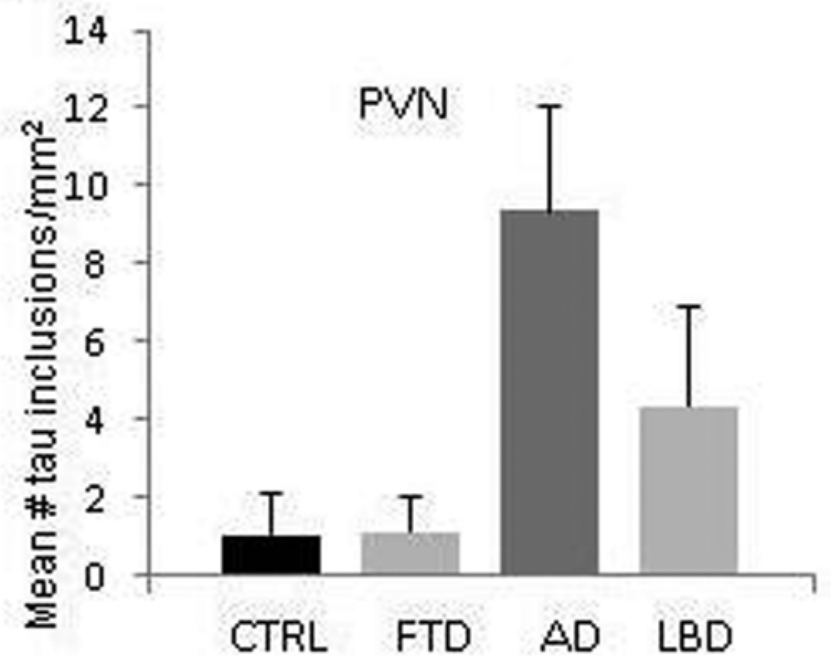

b

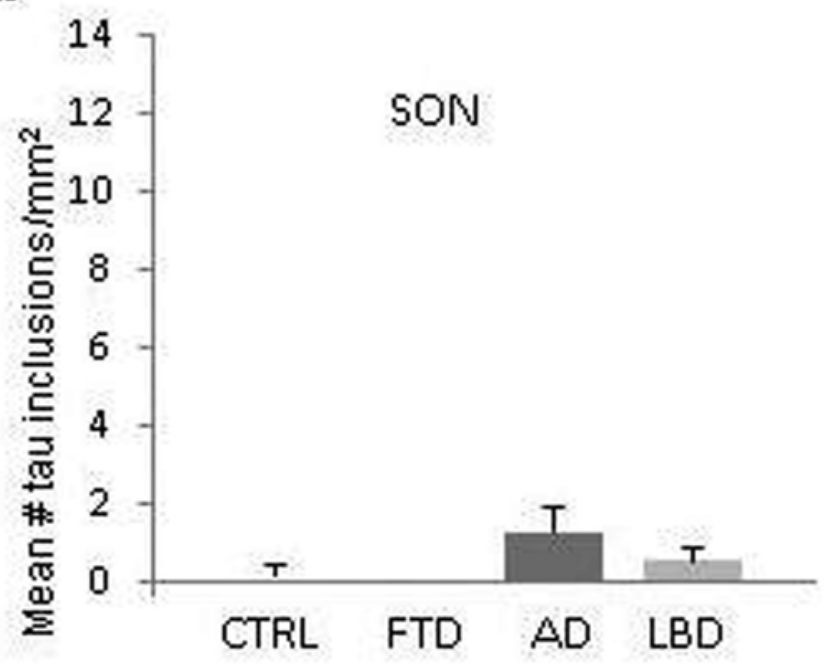

Figure 1: a) Mean tau counts per $\mathrm{mm}^{2}$ in the paraventricular nucleus demonstrating increased tau inclusions in Alzheimer's disease (AD) compared to Controls $(C T L R)$, and Frontotemporal Dementia-TDP-43+ (FTD). b) Mean tau counts per $\mathrm{mm}^{2}$ in the supraoptic nucleus demonstrating the absence of Alzheimer related tau inclusions. Lewy body dementia (LBD) 
Table: Clinical data and measures of protein inclusions per $\mathbf{m m}^{2}$ in the paraventricular and supraoptic hypothalamic nuclei

\begin{tabular}{|c|c|c|c|c|c|c|c|c|c|c|c|c|c|}
\hline \multirow[b]{2}{*}{ Diagnosis } & \multirow[b]{2}{*}{ Age at death } & \multirow[b]{2}{*}{ Gender } & \multirow[b]{2}{*}{ FTLD subtype } & \multirow[b]{2}{*}{ FTD clinical subtype } & \multirow[b]{2}{*}{ Years III } & \multicolumn{4}{|c|}{ PVN } & \multicolumn{4}{|c|}{ SON } \\
\hline & & & & & & TDP-43 & Tau & $\begin{array}{l}\text { alpha- } \\
\text { synuclein }\end{array}$ & ubiqutin & TDP-43 & Tau & $\begin{array}{l}\text { alpha- } \\
\text { synuclein }\end{array}$ & ubiqutin \\
\hline FTD & 63 & $\mathrm{~F}$ & FTLD with motor neuron disease and TDP- 43 proteinopathy & bvFTD with motor neuron disease & 6 & 0.00 & 0.74 & 0.00 & 7.45 & 0.00 & 0.00 & 0.00 & 1.11 \\
\hline FTD & 81 & $\mathrm{~F}$ & FTLD with TDP-43 proteinopathy & primary progressive aphasia & 18 & 0.00 & 0.00 & 0.00 & 4.31 & 0.00 & 0.00 & 0.00 & 0.00 \\
\hline FTD & 74 & $\mathrm{~F}$ & FTLD with TDP-43 proteinopathy & bvFTD, logopenic, apathetic variant & 6 & 0.00 & 0.57 & 0.00 & 0.00 & & & la & \\
\hline FTD & 60 & M & FTLD with TDP-43 proteinopathy & bvFTD with parkinsonism & 8 & & & ala & & 0.00 & 0.00 & 0.00 & 3.74 \\
\hline FTD & 79 & $\mathrm{~F}$ & FTLD with TDP-43 proteinopathy & semantic dementia & 17 & 0.00 & 0.00 & 0.00 & 0.00 & 0.00 & 0.00 & 0.00 & 0.57 \\
\hline FTD & 58 & M & FTLD with TDP-43 proteinopathy & semantic dementia & 22 & 0.00 & 0.00 & 0.00 & 4.09 & 0.00 & 0.00 & 0.00 & 0.00 \\
\hline FTD & 51 & $\mathrm{~F}$ & FTLD with motor neuron disease and TDP- 43 proteinopathy & bvFTD & 4 & 0.00 & 0.00 & 0.00 & 4.14 & 0.00 & 0.00 & 0.00 & 0.00 \\
\hline FTD & 76 & $\mathrm{~F}$ & FTLD with TDP-43 proteinopathy and hippocampal sclerosis & bvFTD & n/a & 0.00 & 0.00 & 0.00 & 0.00 & 0.00 & 0.00 & 0.00 & 0.00 \\
\hline LBD & 67 & M & & & & 0.00 & 0.00 & 0.48 & 2.38 & 0.00 & 0.00 & 1.00 & 1.30 \\
\hline LBD & 76 & M & & & & 0.00 & 4.55 & 0.00 & 1.14 & & & la & \\
\hline LBD & 77 & M & & & & 0.00 & 3.27 & 0.00 & 5.45 & 0.00 & 1.45 & 2.00 & 0.00 \\
\hline LBD & 80 & M & & & & 0.00 & 14.01 & 0.00 & 3.11 & 0.00 & 0.64 & 3.00 & 0.64 \\
\hline LBD & 53 & M & & & & 0.00 & 0.00 & 1.70 & 0.57 & 0.00 & 0.00 & 0.00 & 0.94 \\
\hline$A D$ & 87 & M & & & & 0.00 & 5.99 & 0.00 & 0.00 & 0.00 & 0.65 & 0.00 & 0.65 \\
\hline$A D$ & 75 & $\mathrm{~F}$ & & & & 0.00 & 6.80 & 0.00 & 2.72 & 0.00 & 0.00 & 0.00 & 1.03 \\
\hline$A D$ & 80 & $\mathrm{~F}$ & & & & 0.00 & 14.72 & 0.00 & 0.00 & 0.00 & 0.00 & 0.00 & 0.00 \\
\hline$A D$ & 73 & M & & & & 0.00 & 2.98 & 0.00 & 0.99 & 0.00 & 0.56 & 0.00 & 0.56 \\
\hline$A D$ & 76 & $\mathrm{~F}$ & & & & 0.00 & 13.05 & 0.00 & 0.00 & 0.00 & 0.00 & 0.00 & 2.72 \\
\hline$A D$ & 85 & M & & & & 0.00 & 29.55 & 0.00 & 8.87 & 0.00 & 6.93 & 1.00 & 5.94 \\
\hline$A D$ & 74 & M & & & & 0.00 & 0.33 & 0.00 & 0.33 & 0.00 & 0.33 & 0.00 & 0.00 \\
\hline$A D$ & 56 & $\mathrm{~F}$ & & & & 0.00 & 2.85 & 0.00 & 0.95 & 0.00 & 2.44 & 0.00 & 0.70 \\
\hline$A D$ & 87 & $\mathrm{~F}$ & & & & 0.00 & 7.71 & 0.00 & 3.17 & 0.00 & 0.61 & 0.00 & 1.84 \\
\hline$A D$ & 86 & M & & & & 0.00 & 7.57 & 0.00 & 0.00 & 0.00 & 2.20 & 0.00 & 3.67 \\
\hline$A D$ & 68 & $\mathrm{~F}$ & & & & 0.00 & 9.77 & 0.00 & 0.00 & 0.00 & 0.00 & 0.00 & 26.37 \\
\hline CTRL & 68 & M & & & & & & 1/a & & 0.00 & 0.00 & 0.00 & 0.68 \\
\hline CTRL & 66 & $\mathrm{~F}$ & & & & 0.00 & 7.20 & 0.00 & 10.28 & 0.00 & 2.76 & 0.00 & 8.27 \\
\hline CTRL & 73 & M & & & & 0.00 & 0.00 & 0.00 & 3.55 & & & /a & \\
\hline CTRL & 53 & M & & & & 0.00 & 0.00 & 0.00 & 1.12 & 0.00 & 0.00 & 0.00 & 0.00 \\
\hline CTRL & 57 & $\mathrm{~F}$ & & & & 0.00 & 0.00 & 0.00 & 11.26 & 0.00 & 2.32 & 0.00 & 30.17 \\
\hline CTRL & 82 & M & & & & 0.00 & 0.29 & 0.00 & 0.88 & 0.00 & 0.00 & 0.00 & 33.42 \\
\hline CTRL & 78 & M & & & & & & la & & 0.00 & 0.00 & 0.00 & 1.50 \\
\hline CTRL & 80 & $\mathrm{~F}$ & & & & 0.00 & 0.00 & 0.00 & 1.66 & 0.00 & 0.00 & 0.00 & 3.63 \\
\hline CTRL & 63 & $\mathrm{~F}$ & & & & 0.00 & 0.00 & 0.00 & 6.62 & 0.00 & 0.00 & 0.00 & 2.82 \\
\hline
\end{tabular}

FTLD = frontotemporal lobar degeneration; TDP-43 = tar DNA-binding protein 43; bvFTD = behavioural variant FTD; FTD = Frontotemporal dementia; LBD = Lewy Body Dementia; $\mathrm{AD}=$ Alzheimer's disease; $\mathrm{CTRL}=\mathrm{Control} ; \mathrm{n} / \mathrm{a}=$ not available

were then re-examined, and if these nuclei were still absent or insufficient for quantification, these cases were excluded from the study. After reviewing cases on the basis of final autopsy diagnosis and availability of hypothalamic tissue, 35 cases were selected [eight FTLD with TDP-43 proteinopathy (including 2 with FTLD plus motor neuron disease), 11 Alzheimer's disease, 5 Lewy body dementia, and 9 age-matched controls (see Table)]. The paraffin sections from cases with SON and, or the PVN present were submitted for immunohistochemistry with primary antibodies to phosphorylated tau (AT8, ThermoScientic, 1:400) alpha-synuclein (Zymed, 1;50), ubiquitin (Dako, 1:200), and TDP-43 (ProtemTechGroup, 1:1000) utilizing the ImmPRESS Peroxidase Polymer Detection Kit from Vector Laboratories, Southfield, MI. The area of each nucleus (SON or PVN) was determined using an Olympus BX51 microscope linked to SPOT software and manually tracing the outline of the nucleus. The neuronal density per nucleus was determined by counting the number of neurons utilizing the same software within the area delineated and the density was represented as neurons (nuclei) per $\mathrm{mm}^{2}$. The SON and PVN were examined for inclusions for each of the immunostains; an inclusion was counted at 60X10 magnification if it was clearly within the boundaries of the SON or PVN. The number of tau, alpha-synuclein, ubiquitin or TDP43 inclusions was quantified and normalized by the individual area of each nucleus. For TDP-43, nuclear staining was used as an internal positive control.

Statistical analysis: One-way analysis of variance (ANOVAs) with diagnosis as the between subject factor were performed for each nucleus (SON and PVN) and immunostain (TDP-43, tau, alpha-synuclein, ubiquitin) using the SPSS program. Additional ANOVAs with diagnosis as the between subject factor were conducted on the number of neurons per nucleus for the SON and PVN. Significant main effects were followed up with posthoc t-tests between each group, and independent samples t-tests were conducted between the dementia groups and controls. 


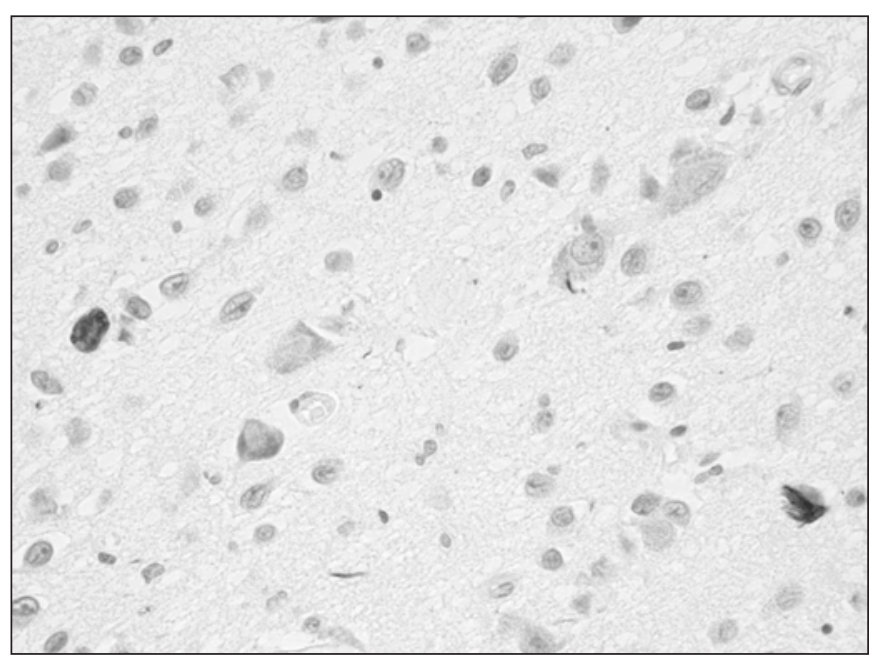

Figure 2: Histological section demonstrating tau-paired helical filament immunostaining in the paraventricular nucleus of a patient with Alzheimer's disease (x400 magnification).

\section{RESULTS}

\section{Paraventricular Nucleus}

The PVN was available for examination in eight patients with FTD TDP-43, ten patients with Alzheimer's disease, five patients with Lewy body dementia and seven controls. In the PVN, the one-way ANOVAs demonstrated a significant main effect of diagnosis for the number of tau inclusions $(F(3,29)=$ $4.1, \mathrm{p}<0.05$ and for the number of alpha-synuclein inclusions $(\mathrm{F}(3,29)=3.1, \mathrm{p}<0.05)$. For tau inclusions, post-hoc t-tests demonstrated significant differences between $\mathrm{AD}$ and controls ( $\mathrm{AD}>$ controls) $(\mathrm{t}(15)=2.5 ; \mathrm{p}<0.05)$, and $\mathrm{AD}$ and FTD groups $(\mathrm{AD}>\mathrm{FTD})(\mathrm{t}(17)=2.4 ; \mathrm{p}<0.05)$, while $\mathrm{AD}$ and $\mathrm{LBD}$ were not significantly different (Figure 1a). The tau immunohistochemistry demonstrated neurofibrillary tangles, mostly of the globose types and neuropil threads in the affected areas (Figure 2). Occasional round to oval intracytoplasmic inclusions were also observed in the neurons which do not resemble any classical neurofibrillary tangles.

Although post-hoc t-tests demonstrated a trend of greater alpha-synuclein inclusions in LBD vs. $\mathrm{AD}(\mathrm{t}(13)=1.2, \mathrm{p}<0.07)$ (Figure 3a), no significant differences in alpha-synuclein inclusions were found for LBD vs. controls or LBD vs FTD. There were no significant differences in neuron density ( $F$ $(3,29)=0.19, \mathrm{p}=\mathrm{ns})$ (Figure 1-B), or mean number of ubiquitin $(\mathrm{F}(3,29)=1.9, \mathrm{p}=\mathrm{ns})$, or TDP-43 $(\mathrm{F}(3,29)=0, \mathrm{p}=\mathrm{ns})$ inclusions in the dementia groups compared to controls (Table). Of interest, there were no TDP-43+ inclusions found in the PVN of any case.

\section{Supraoptic Nucleus}

The SON was available for examination in seven patients with FTD TDP-43, 11 patients with Alzheimer's disease, four patients with Lewy body dementia and eight controls. The oneway ANOVAs demonstrated a significant main effect of diagnosis for alpha-synuclein inclusions $(\mathrm{F}(3,29)=18.2$, $\mathrm{p}<0.05$ ) (Figure 2b). Follow up t-tests between LBD and the other groups demonstrated increased alpha-synuclein inclusions in LBD compared to patients with Alzheimer's disease $(\mathrm{t}(13)=4.6, \mathrm{p}<0.05)$, FTD TDP-43 $(\mathrm{t}(9)=4.4, \mathrm{p}<0.05)$ and controls $(t(10)=4.7, p<0.05)$ (Figure 3$)$. In the affected areas, the alpha-synuclein immunohistochemistry demonstrated Lewy neurites, some of which appeared more globular, suggestive of

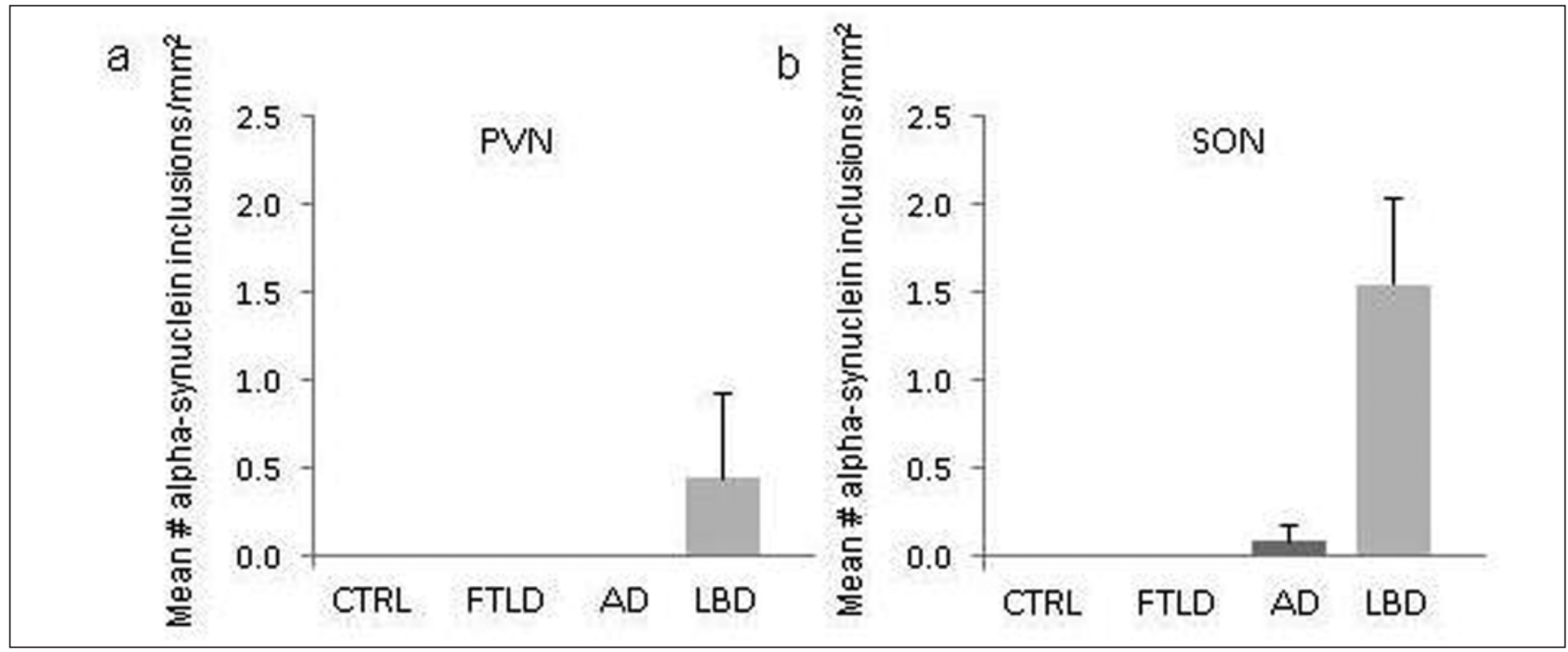

Figure 3: a) Mean alpha-synuclein counts per $\mathrm{mm}^{2}$ in the paraventricular nucleus, demonstrating the relative absence of inclusions in Lewy body disease. b) Mean alpha-synuclein positive inclusions in the supraoptic nucleus demonstrating increased inclusions in Lewy body disease compared to other groups. Controls (CTLR), Alzheimer's Disease (AD) Frontotemporal Dementia (FTLD), Lewy body dementia (LBD) 


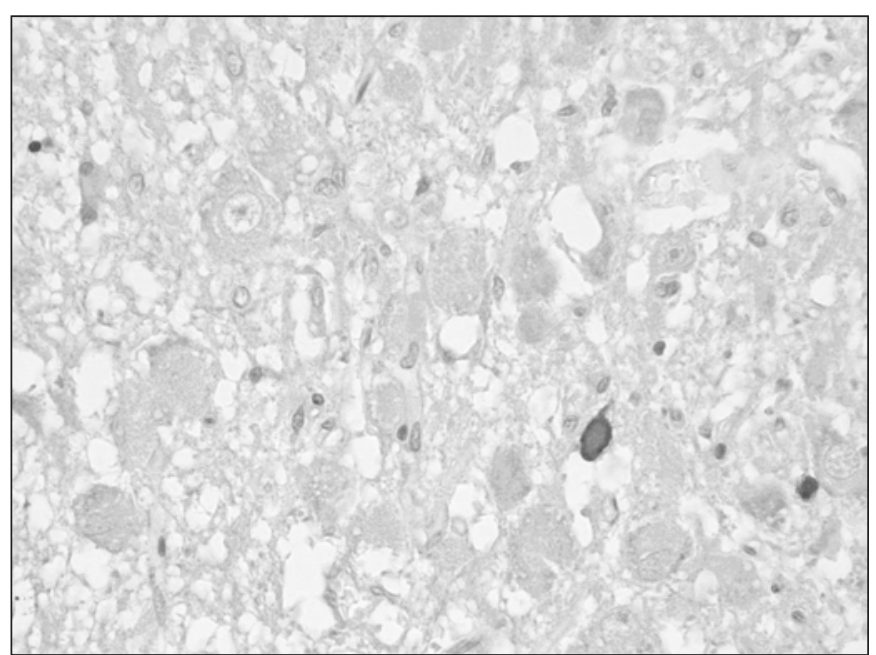

Figure 4: Histological section demonstrating alpha-synuclein immunostaining in the supraoptic nucleus of a patient with Lewy body disease (x400 magnification).

intraneuritic Lewy bodies, but no definite Lewy bodies of cortical or subcortical variants were identified (Figure 4). The remaining ANOVAs indicated that there were no significant differences or trends in the mean number of tau (Figure 1b), TDP-43, or ubiquitin inclusions or neuron density in the groups. There were no other trends of difference between AD and FTD groups and controls. Of interest, there were no TDP-43+ inclusions found in the SON of any case.

\section{Discussion}

The present study evaluated the neuronal integrity and presence of neurodegenerative pathology in the two oxytocin producing nuclei of the hypothalamus across the three main neurodegenerative dementias. Counter to our predictions, in patients with FTD (TDP-43+) we did not find significant pathology in either nucleus. In contrast, patients with Alzheimer's disease demonstrated significant tau pathology in the PVN, but not the SON, compared to controls and FTD patients. Increased alpha-synuclein inclusions were found in patients with Lewy body dementia compared to controls in the SON but not the PVN. Neuronal counts did not differ in either nucleus between the dementia groups and the controls. The present results demonstrate for the first time the integrity of the SON in FTLD with TDP-43 proteinopathy. They also extend prior reports of pathologic changes in the hypothalamus in Alzheimer's disease and LBD in the hypothalamus by demonstrating differential susceptibility of these two nuclei to the hallmark pathologic inclusions of these disorders.

In patients with Alzheimer's disease, cell counts and neuronal numbers and volume are generally preserved in the SON and $\mathrm{PVN}^{37}$. Interestingly, the SON appears resistant to tau pathology in Alzheimer's disease, while the PVN shows Alzheimer related tau+ and dystrophic neurites ${ }^{38,39}$. Results from the present study support this pattern, demonstrating that more tau pathology is found in the PVN of Alzheimer's disease patients than in controls, as well as patients with FTLD TDP-43 or LBD. Furthermore, the lack of significant Alzheimer's disease related tau pathology in the SON in the present study offers further support for suggestions that this nucleus may be preferentially resistant to AD related changes. Further investigation of the differential vulnerability of these two hypothalamic nuclei to the same neurodegenerative disease may provide further insights into the selective vulnerability of other regions of CNS to Alzheimer disease changes.

In contrast to the pattern observed in Alzheimer's disease, the SON does not show resistance to pathology in other neurodegenerative diseases. In patients with Parkinson's disease, Lewy bodies have been reported in the SON in up to $26 \%$ of patients ${ }^{40}$. In Parkinson's disease, Lewy bodies have not been previously described in the PVN, though neuronal counts were found to be reduced compared to controls ${ }^{41}$. Reports on the integrity of these nuclei and presence of Lewy bodies in patients with Lewy body dementia have not been previously reported. The current results support the pattern of findings in patients with Parkinson's disease, and demonstrate the presence of increased Lewy bodies in the SON but not the PVN in the hypothalamus of patients with Lewy body dementia. This pattern is intriguing as it is the opposite of the differential susceptibility of these nuclei described above in the patients with Alzheimer's disease. Further study of biochemical differences between the PVN and SON in Lewy body dementia and Alzheimer's disease that may confer such resistance to specific neuronal inclusions could not only elucidate mechanisms for the selective vulnerability of other neurons in the CNS to these processes but also identify novel potential treatment targets for conferring neuronal resistance to alpha-synuclein or tau pathology.

The lack of significant FTLD TDP-43 pathology in the SON and PVN indicates that neuronal damage and loss within these nuclei is not a contributing factor to the abnormal social behavioural symptoms characteristic of the disorder, at least in this pathologic subtype. As our sample included only patients with the TDP-43 subtypes of FTD, conclusions about the involvement of the SON in other FTLD subtypes such as FTLD with tauopathy or fused in sarcoma (FUS) proteinopathy will require additional study. While the aim of the present study was to characterize the presence of neuropathology in the PVN and SON, the two oxytocin producing nuclei of the hypothalamus, other neurons in these nuclei produce vasopressin. In the PVN, approximately $50 \%$ of the neurons secrete oxytocin, while in the SON approximately $10-15 \%$ secrete oxytocin ${ }^{42,43}$. Identification of oxytocin specific neurons in these nuclei was not possible due to the prolonged time in formalin for many of the samples, which precluded reliable staining for either the oxytocin peptide or receptor. Thus, it is possible that a selective reduction in oxytocin producing neurons may not be detected if other neuronal subtypes in the nuclei are preserved, particularly in the SON. Another consideration in the interpretation of our results is the finding of preserved neuronal counts despite the presence of increased Alzheimer disease pathology in PVN and LBD in the SON. However, this pattern is consistent with prior studies demonstrating similar dissociations between the presence of neurodegenerative pathology and neuronal cell loss in hypothalamic nuclei in Alzheimer's disease and Parkinson's disease $^{38,41,44}$. Thus, whether the inclusions found in the present 
study in $\mathrm{AD}$ and LBD patients result in any significant impairment of the function of these nuclei cannot be presumed. Future studies evaluating additional protein markers of neuronal injury would further illuminate whether inclusions are associated with any signals of neuronal degeneration.

In summary, we found that the two oxytocin producing nuclei of the hypothalamus, the SON and PVN, lack significant pathologic changes associated with FTLD with TDP-43 proteinopathy. In patients with $\mathrm{AD}$ and $\mathrm{LBD}$, distinct patterns of disease related pathology in the PVN vs the $\mathrm{SON}$ raise intriguing questions for the relationship between specific inclusion types and selective vulnerability or resistance of these two hypothalamic neuronal populations. Future studies are required to assess whether damage to the SON and PVN in other subtypes of FTLD, or damage to oxytocinergic projections from the hypothalamic nuclei within the medial prefrontal cortex, amygdala and striatum may be implicated in the social deficits of FTD.

\section{ACKNOWLEDGEMENTS}

This research was supported by Summer Research Training Program, the Hazel Soper Foundation at the University of Western Ontario.

\section{REFERENCES}

1. Kertesz A, Davidson W, Fox H. Frontal behavioral inventory: diagnostic criteria for frontal lobe dementia. Can J Neurol Sci. 1997 Feb;24(1):29-36.

2. Miller BL, Darby A, Benson DF, Cummings JL, Miller MH. Aggressive, socially disruptive and antisocial behaviour associated with fronto-temporal dementia. Br J Psychiatry. 1997 Feb;170:150-4.

3. Neary D, Snowden JS, Gustafson L, et al. Frontotemporal lobar degeneration: a consensus on clinical diagnostic criteria. Neurology. 1998 Dec;51(6):1546-54.

4. Rankin KP, Gorno-Tempini ML, Allison SC, et al. Structural anatomy of empathy in neurodegenerative disease. Brain. 2006 Nov;129(Pt 11):2945-56.

5. Rankin KP, Kramer JH, Mychack P, Miller BL. Double dissociation of social functioning in frontotemporal dementia. Neurology. 2003 Jan 28;60(2):266-71.

6. Fernandez-Duque D, Black SE. Impaired recognition of negative facial emotions in patients with frontotemporal dementia. Neuropsychologia. 2005;43(11):1673-87.

7. Keane J, Calder AJ, Hodges JR, Young AW. Face and emotion processing in frontal variant frontotemporal dementia. Neuropsychologia. 2002;40(6):655-65.

8. Diehl-Schmid J, Pohl C, Ruprecht C, Wagenpfeil S, Foerstl H, Kurz A. The Ekman 60 Faces Test as a diagnostic instrument in frontotemporal dementia. Arch Clin Neuropsychol. 2007 May; 22(4):459-64.

9. Gregory C, Lough S, Stone V, et al. Theory of mind in patients with frontal variant frontotemporal dementia and Alzheimer's disease: theoretical and practical implications. Brain. 2002 Apr;125(Pt 4):752-64.

10. Lough S, Kipps CM, Treise C, Watson P, Blair JR, Hodges JR. Social reasoning, emotion and empathy in frontotemporal dementia. Neuropsychologia. 2006;44(6):950-8.

11. Dierickx K, Vandesande F. Immunocytochemical demonstration of separate vasopressin-neurophysin and oxytocin-neurophysin neurons in the human hypothalamus. Cell Tissue Res. 1979 Feb 15;196(2):203-12.

12. Goodson JL, Thompson RR. Nonapeptide mechanisms of social cognition, behavior and species-specific social systems. Curr Opin Neurobiol. 2010 Dec;20(6):784-94.
13. Ross HE, Cole CD, Smith Y, et al. Characterization of the oxytocin system regulating affiliative behavior in female prairie voles. Neuroscience. 2009 Sep 15;162(4):892-903.

14. Schorscher-Petcu A, Dupre A, Tribollet E. Distribution of vasopressin and oxytocin binding sites in the brain and upper spinal cord of the common marmoset. Neurosci Lett. 2009 Sep $25 ; 461(3): 217-22$.

15. Smeltzer MD, Curtis JT, Aragona BJ, Wang Z. Dopamine, oxytocin, and vasopressin receptor binding in the medial prefrontal cortex of monogamous and promiscuous voles. Neurosci Lett. 2006 Feb 13;394(2):146-51.

16. Wang Z, Moody K, Newman JD, Insel TR. Vasopressin and oxytocin immunoreactive neurons and fibers in the forebrain of male and female common marmosets (Callithrix jacchus). Synapse. 1997 Sep;27(1):14-25.

17. Mann DM, South PW, Snowden JS, Neary D. Dementia of frontal lobe type: neuropathology and immunohistochemistry. J Neurol Neurosurg Psychiatry. 1993 Jun;56(6):605-14.

18. Munoz DG, Dickson DW, Bergeron C, Mackenzie IR, Delacourte A, Zhukareva V. The neuropathology and biochemistry of frontotemporal dementia. Ann Neurol. 2003;54 Suppl 5:S24-8.

19. Cairns NJ, Bigio EH, Mackenzie IR, et al. Neuropathologic diagnostic and nosologic criteria for frontotemporal lobar degeneration: consensus of the Consortium for Frontotemporal Lobar Degeneration. Acta Neuropathol. 2007 Jul;114(1):5-22.

20. Donaldson ZR, Young LJ. Oxytocin, vasopressin, and the neurogenetics of sociality. Science. 2008 Nov 7;322(5903):900-4.

21. Insel TR, Young LJ. The neurobiology of attachment. Nat Rev Neurosci. 2001 Feb;2(2):129-36.

22. Pedersen CA, Caldwell JD, Peterson G, Walker CH, Mason GA. Oxytocin activation of maternal behavior in the rat. Ann NY Acad Sci. 1992 Jun 12;652:58-69.

23. Kendrick KM, Keverne EB, Baldwin BA. Intracerebroventricular oxytocin stimulates maternal behaviour in the sheep. Neuroendocrinology. 1987 Jun;46(1):56-61.

24. Fahrbach SE, Morrell JI, Pfaff DW. Possible role for endogenous oxytocin in estrogen-facilitated maternal behavior in rats. Neuroendocrinology. 1985 Jun;40(6):526-32.

25. Baumgartner T, Heinrichs M, Vonlanthen A, Fischbacher U, Fehr E. Oxytocin shapes the neural circuitry of trust and trust adaptation in humans. Neuron. 2008 May 22;58(4):639-50.

26. Kosfeld M, Heinrichs M, Zak PJ, Fischbacher U, Fehr E. Oxytocin increases trust in humans. Nature. 2005 Jun 2;435(7042):673-6.

27. Hurlemann R, Patin A, Onur OA, et al. Oxytocin enhances amygdala-dependent, socially reinforced learning and emotional empathy in humans. J Neurosci. 2010 Apr 7;30(14):4999-5007.

28. Di Simplicio M, Massey-Chase R, Cowen PJ, Harmer CJ. Oxytocin enhances processing of positive versus negative emotional information in healthy male volunteers. J Psychopharmacol. 2009 May;23(3):241-8.

29. Guastella AJ, Kenyon AR, Alvares GA, Carson DS, Hickie IB. Intranasal arginine vasopressin enhances the encoding of happy and angry faces in humans. Biol Psychiatry. 2010 Jun 15; 67 (12): $1220-2$.

30. Marsh AA, Yu HH, Pine DS, Blair RJ. Oxytocin improves specific recognition of positive facial expressions. Psychopharmacology (Berl). 2010 Apr;209(3):225-32.

31. Domes G, Heinrichs M, Michel A, Berger C, Herpertz SC. Oxytocin improves "mind-reading" in humans. Biol Psychiatry. 2007 Mar 15;61(6):731-3.

32. Hollander E, Bartz J, Chaplin W, et al. Oxytocin increases retention of social cognition in autism. Biol Psychiatry. 2007 Feb 15; 61 (4):498-503.

33. Hollander E, Novotny S, Hanratty M, et al. Oxytocin infusion reduces repetitive behaviors in adults with autistic and Asperger's disorders. Neuropsychopharmacology. 2003 Jan;28 (1):193-8

34. Stopa EG, Volicer L, Kuo-Leblanc V, et al. Pathologic evaluation of the human suprachiasmatic nucleus in severe dementia. J Neuropathol Exp Neurol. 1999 Jan;58(1):29-39.

35. Braak H, Braak E. Pick's disease: cytoskeletal changes in the hypothalamic lateral tuberal nucleus. Brain Res. 1998 Aug 17; 802(1-2):119-24. 
36. Piguet O, Petersen A, Yin Ka Lam B, et al. Eating and hypothalamus changes in behavioral-variant frontotemporal dementia. Ann Neurol. 2011 Feb;69(2):312-9.

37. Goudsmit E, Hofman MA, Fliers E, Swaab DF. The supraoptic and paraventricular nuclei of the human hypothalamus in relation to sex, age and Alzheimer's disease. Neurobiol Aging. 1990 SepOct:11(5):529-36.

38. Swaab DF, Grundke-Iqbal I, Iqbal K, Kremer HP, Ravid R, van de Nes JA. Tau and ubiquitin in the human hypothalamus in aging and Alzheimer's disease. Brain Res. 1992 Sep 11;590(1-2): $239-49$.

39. van de Nes JA, Kamphorst W, Ravid R, Swaab DF. The distribution of Alz-50 immunoreactivity in the hypothalamus and adjoining areas of Alzheimer's disease patients. Brain. $1993 \mathrm{Feb} ; 116$ (Pt 1): 103-15.

40. Langston JW, Forno LS. The hypothalamus in Parkinson disease. Ann Neurol. 1978 Feb;3(2):129-33.
41. Purba JS, Hofman MA, Swaab DF. Decreased number of oxytocinimmunoreactive neurons in the paraventricular nucleus of the hypothalamus in Parkinson's disease. Neurology. 1994 Jan;44 (1):84-9.

42. Wierda M, Goudsmit E, Van der Woude PF, et al. Oxytocin cell number in the human paraventricular nucleus remains constant with aging and in Alzheimer's disease. Neurobiol Aging. 1991 Sep-Oct;12(5):511-6.

43. Fliers E, Swaab DF, Pool CW, Verwer RW. The vasopressin and oxytocin neurons in the human supraoptic and paraventricular nucleus; changes with aging and in senile dementia. Brain Res. 1985 Sep 2;342(1):45-53.

44. Kremer HP, Bots GT. Lewy bodies in the lateral hypothalamus: do they imply neuronal loss? Mov Disord. 1993 Jul;8(3):315-20. 